\title{
Redes empresariales de Francisco Ignacio de Yraeta e Isidro Antonio de Icaza durante el periodo de expansión del tráfico de cacao de Guayaquil, 1774-1783
}

\section{Business networks of Francisco Ignacio de Yraeta and Isidro Antonio de Icaza during the expansion period of the Guayaquil cocoa traffic, 1774-1783}

Guillermina del Valle Pavón

Instituto de Investigaciones Dr. José María Luis Mora, México ${ }^{1}$

\section{Resumen}

Se analiza cómo el incremento del tráfico de cacao de Guayaquil en Nueva España, que generó la apertura comercial de 1774 y la guerra anglo-española de 1779-1783, dio lugar a la movilidad de los hermanos Icaza de Panamá a Guayaquil y a Nueva España. Asimismo, se examinan los vínculos interpersonales que establecieron Francisco Ignacio de Yraeta e Isidro Antonio de Icaza y cómo intercambiaron cantidades crecientes del grano ecuatoriano por géneros de Europa y Asia, con base en complejas redes familiares, de paisanaje y negocios que generaban la confianza requerida por la magnitud del

1 El Instituto imparte programas académicos, se dedica a la investigación en historia y ciencias sociales, y forma parte de los centros públicos del Consejo Nacional de Ciencia y Tecnología (CONACIT) de México. Contacto: minadelvalle17@gmail.com 
comercio que realizaban, la necesidad de recurrir al crédito y la lentitud con que circulaba la información.

Palabras clave: redes comerciales, cacao, comercio, océano Pacífico, reformas borbónicas, Guayaquil

\section{Abstract}

The increase in Guayaquil's cocoa traffic in New Spain is analyzed and how it brought about the commercial opening of 1776 and the Anglo-Spanish war of 1779-1783, giving rise to the mobility of the Icaza brothers from Panama to Guayaquil and New Spain. Likewise, the interpersonal links established by Francisco Ignacio de Yraeta and Isidro Antonio de Icaza are examined, as well as how they exchanged increasing amounts of the Ecuadorian bean for goods from Europe and Asia, based on complex family networks, nationhood, and businesses that rendered the confidence required by the magnitude of the trade they carried out, the need to resort to credit, and the slowness of information circulation.

Key words: trade networks, cacao, trade, Pacific Ocean, Bourbon reforms, Guayaquil

152 El comercio entre Nueva España y Perú estuvo restringido durante la mayor parte del período colonial, porque propiciaba el intercambio de bienes asiáticos por plata andina que se "perdía" en el Oriente junto con la mexicana. Sin embargo, los fuertes intereses implicados en el comercio del azogue y el cacao de Guayaquil mantuvieron el tráfico intervirreinal por el Pacífico con licencias y de manera ilícita. Las compras del cacao de Guayaquil en Nueva España aumentaron 
de manera notable a partir de 1774, cuando se autorizó el comercio restringido en los principales puertos del Pacífico hispanoamericano. No obstante, fue la coyuntura de la guerra contra Gran Bretaña (1779-1783) la que intensificó de manera espectacular el tráfico por la mar del sur. Contreras Carranza (1987, p. 55) encontró que las exportaciones del grano ecuatoriano al puerto de Acapulco presentaron un veloz crecimiento a partir de la década de 1780 , fenómeno que confirmó Miño Grijalva (2013, pp. 112-113, 115). Bonialian (2012, pp. 405-441) atribuyó el dinámico crecimiento que presentó dicho tráfico durante los años del conflicto bélico al hecho de que la ciudad de México se transformó en el núcleo que articuló el tráfico transatlántico de las flotas y el transpacífico del galeón de Manila con los flujos intercoloniales de la mar del sur, como consecuencia del desabasto que ocasionaron los bloqueos por parte de los ingleses.

En Nueva España, el tráfico del cacao de Guayaquil fue monopolizado por un pequeño grupo de poderosos mercaderes de la ciudad de México que lo contrataba en grandes cantidades, lo que se incrementó con la apertura comercial limitada de 1774 (Borchart 1984: 112-114, Del Valle Pavón, 2010). Entre dichos almaceneros, destacó Francisco Ignacio de Yraeta, estudiado por Cristina Torales Pacheco (1985) y el equipo que coordinó, a partir de la documentación sobre la casa comercial de dicho mercader. Stanley Stein (2001) analizó la correspondencia que Yraeta sostuvo con su sobrino Gabriel de Yturbe. Y Soler Lizarazo (2010, pp. 55-232) escudriñó la correspondencia que Yraeta intercambió con tratantes de Hispanoamérica y España en el periodo 17691797. Dichos historiadores dieron cuenta de las extraordinarias oportunidades que tuvo el almacenero para contratar durante la guerra anglo-española; sin embargo, no considera- 
ron las políticas de excepción que permitieron el intercambio creciente de géneros de Asia y Europa por plata potosina y cacao de Guayaquil.

En este artículo, se analiza la forma en que la normatividad comercial dictada durante el periodo 1774-1783 incrementó el tráfico del cacao de Guayaquil en Nueva España, en particular durante el conflicto bélico contra Gran Bretaña. Para ello se examinan, desde una perspectiva empresarial, los negocios de los mercaderes de origen vizcaíno Francisco Ignacio de Yraeta e Isidro Antonio de Icaza, quien, luego de haberse desplazado de Panamá a Guayaquil, se estableció en México a raíz del auge comercial propiciado por la guerra. Se muestra el modo en que la apertura comercial restringida y las medidas excepcionales introducidas durante la conflagración bélica dieron lugar a la movilidad de los miembros de la familia Icaza y cómo el tráfico del grano ecuatoriano se articuló a partir de complejas redes familiares, profesionales $\mathrm{y}$ de paisanaje, al tiempo que fue favorecido por las relaciones políticas que ambos mercaderes cultivaron con las principales autoridades del virreinato y con otros almaceneros. Asimismo, se estudia el papel que desempeñó el consulado de México en la aplicación de la normatividad que posibilitó el intercambio de efectos asiáticos y europeos por cacao de Guayaquil y plata andina en grandes cantidades durante el

154 conflicto contra Gran Bretaña.

\section{Comercio informal del cacao de Guayaquil y su consumo en Nueva Espańa}

En los primeros dos tercios del siglo XVIII, a pesar de la prohibición del tráfico entre los virreinatos de Perú y Nueva 
España ${ }^{2}$ se mantuvo la contratación del cacao de Guayaquil. Esto se explica por dos razones fundamentales, primero, porque la necesidad que tenían los mineros novohispanos del mercurio para refinar los metales daba lugar al tráfico del mercurio de Huancavelica, con el que se comerciaba el grano. $Y$ en segundo lugar, porque la gran demanda del cacao ecuatoriano que había en el virreinato septentrional propiciaba las introducciones ilícitas. Junto con los permisos especiales para contratar el grano guayaquileño, que se otorgaban principalmente durante los conflictos bélicos, se recurría a las arribadas forzosas y al contrabando. La reiterada emisión de leyes en contra del tráfico entre Nueva España y Perú, así como las incautaciones de los cargamentos de navíos procedentes del Callao que arribaban sin licencia a Acapulco y Zihuatanejo, muestran la poca efectividad que tuvieron las prohibiciones de dicho comercio (León Borja y Szászdi, 1964, pp. 7-11, 14-23; Arcila Farías 1975, pp. 254-260, 270-272; Miño Grijalva, 2013, pp. 66-72).

A mediados del siglo XVIII, el cacao de Guayaquil se comercializaba de manera legal en Veracruz, que era el único puerto de Nueva Espańa autorizado para el tráfico con otras colonias. El fruto ecuatoriano que arribaba a dicho puerto tenía un precio mayor que el que se introducía por el Pacífico con licencias especiales, entre otras razones, a causa del costoso transporte por Panamá y la acumulación del pago de derechos en los nu-

2 El tráfico intervirreinal se prohibió en 1631, pero se mantuvo debido a la complacencia de los funcionarios virreinales. Las transgresiones dieron lugar a que el real mandato se reiterara en 1634 y 1636, pero los intercambios solo pudieron suspenderse a raíz de las medidas que tomó el visitador Pedro de Quiroga, con el apoyo del virrey marqués de Cadereytia entre 1637 y 1639 . 
merosos suelos fiscales que atravesaban. El grano guayaquileño se conducía por el litoral del Pacífico a Panamá, en donde se descargaba para acarrearlo en mula a través del istmo hasta Portobello, en donde se embarcaba rumbo a Veracruz (León Borja y Szászdi 1964, pp. 13-14, 24).

Contreras Carranza (1987, pp. 20-21; 1994, pp. 195-198) mostró cómo las exportaciones del cacao guayaquileńo empezaron a crecer hacia la década de 1750 , de manera lenta y gradual, por el aumento de la demanda internacional, en particular de Nueva España, que fue el principal comprador a nivel mundial en el siglo XVIII, así como por los esfuerzos de los vecinos de Guayaquil para compensar los ingresos monetarios que habían perdido a causa de la restricción de las exportaciones de los textiles de Quito. Hasta la década de 1780 el tráfico del cacao guayaquileño con Nueva España fue realizado por los mercaderes-navieros del Callao, que eran miembros del Consulado de Lima con experiencia empresarial, redes y capitales para adquirir grandes cargas del grano y construir y dar mantenimiento a los navíos de gran calado que surcaban el Pacífico (Flores Galindo 1984, pp. 49-50). Los comerciantes de Guayaquil que operaban como sus factores o apoderados mantenían una red de tratantes que compraban el cacao a los productores (Contreras Carranza, 1987, pp. 31-32, 34; 1994, pp. 199-198). Sin embargo,

156 dicho comercio no se hallaba restringido a la iniciativa de los comerciantes asentados en Lima ni a algunos vecinos de Guayaquil que conducían al puerto de Acapulco importantes cantidades de cacao desde las primeras décadas del siglo XVIII (Miño Grijalva, 2013, pp. 67-71).

Algunos libros de alcabalas y registros de la contaduría de la Real Aduana, de 1750 a 1773, mencionan que unos cuantos 
mercaderes de la ciudad de México se especializaban en la contratación de distintos tipos de cacao en grandes cantidades. Estos solían adquirir en un solo año entre mil quinientos y tres mil tercios de cacao de Guayaquil, Maracaibo, Caracas, Tabasco y Cuba, entre otros, cuyo valor iba de cien a doscientos mil pesos. ${ }^{3}$ El monto de las transacciones legales del grano era muy significativo para la economía de la época, lo que se explica en cierta medida, porque remitían parte importante de los granos que traficaban a los puertos de la Península. Los almaceneros de la capital de Nueva España enviaban a sus factores o viajaban personalmente a los puertos de Acapulco, Huatulco y Zihuatanejo para comprar el grano guayaquileño en grandes cantidades a los peruanos y guayaquileños. A mediados del siglo XVIII algunos participaban en el comercio del fruto ecuatoriano mediante el otorgamiento de crédito a los navegantes procedentes del Callao con intereses muy elevados y sólidas garantías debido a los altos riesgos que conllevaban las expediciones a Guayaquil y Lima (Valle Pavón, 2010, pp. 189-191). No obstante, se sabe muy poco sobre las compras que se efectuaban en los puertos de Veracruz y Acapulco de manera legal e ilícita.

El cacao que se comercializaba en Nueva España provenía de Guayaquil, Venezuela y Tabasco. Estos tenían diferentes calidades y precios, por lo que se destinaban a distintos tipos de compradores diferenciados de acuerdo con su capacidad de pago. El cacao ecuatoriano era relativamente abundante y

3 Contaduría de la Real Aduana de México, 5 de julio de 1759, AGN, IC 8-3. Libros de alcabalas, ramo de ultramarinos, años 1770 y 1773 , AGN, AHН 2138, año 1773 y 1006, año de 1778. 
tenía el menor precio, ${ }^{4}$ debido a sus bajos costos de producción, ya que se cultivaba en tierras húmedas muy fértiles y se transportaba a la costa por las corrientes del río Guayas. El grano guayaquileńo era adquirido por los indios, el resto de la gente pobre y de mediana esfera, que era la población más numerosa en Nueva España. Estos consumidores lo demandaban por su bajo precio y por la posibilidad de mezclarlo con mayor cantidad de azúcar - producto que costaba menos-, lo que aumentaba su rendimiento (AGN, CV, 121). Por estas razones, el cacao de Guayaquil se destinaba a "labrar" chocolate barato y a elaborar otros alimentos que eran consumidos en grandes cantidades por indígenas y mestizos, como el champurrado, que se preparaba con cacao y harina de maíz (AGN, CV 121; IC 13). Por estas razones, el cacao del Ecuador se consideraba de baja calidad. Presumimos que este fruto era el que se empleaba en Nueva España como instrumento de cambio por ser el más barato.

Con el cacao de Caracas, Maracaibo y Tabasco, de gusto dulce y consistencia mantecosa, se elaboraba el chocolate más puro, que "distinguía al mejor gusto de la época". Debido a su elevado precio, su consumo se restringía al virrey y a los grupos privilegiados, incluidos la nobleza, los mercaderes, los hacendados, los altos funcionarios de la administración civil y eclesiástica, así como a otras personas que podían pagar por

158 él. Los granos venezolanos eran los más caros, por sus elevados costos de producción y transporte, y porque la Corona, con el propósito de favorecer el monopolio de la Real Compañía Guipuzcoana había restringido su abasto a Nueva Es-

4 Sobre los precios de los diversos granos de cacao en la ciudad de México en algunos años entre 1721 a 1814, véase Miño Grijalva, 2013, Anexo 2, p. 187. 
paña a 21,000 fanegas anuales en 1734 (Arcila Farías, 1975, pp. 34, 67-71, 119-121). Esta circunstancia fue aprovechada por los navieros de Caracas, quienes retrasaban el envío de las embarcaciones cargadas del fruto caraqueño a Veracruz para elevar su precio (AGN, CV 121). A partir de entonces, el insuficiente suministro del grano de Caracas dio lugar a que los mercaderes de México y los encomenderos andaluces compitieran por él en las "ferias" del cacao que se realizaban en Veracruz, lo que ocasionó las protestas del Consulado de México en las décadas de 1740 y 1750 (AHH 269-2 y 2025).

A pesar de las diferencias entre los diversos tipos de cacao, cuando alguno escaseaba era sustituido por otro, aun cuando tuvieran sabor y calidad diferentes. Francisco Ignacio de Yraeta, uno de los mayores tratantes de grano de la ciudad de México, en 1769 escribió a un comerciante de Lima que esperaba el arribo de las embarcaciones procedentes de Guayaquil porque la insuficiencia de los frutos de Caracas, Maracaibo y Tabasco le impedía satisfacer compromisos diversos que tenía en Cádiz (García Díaz, 1985, p. 263). El reducido núcleo de mercaderes traficantes de cacao, que había favorecido el suministro del grano guayaquileńo por Acapulco de manera legal e ilícita para satisfacer la enorme demanda novohispana y remitirlo a la metrópoli, anhelaba el cacao ecuatoriano por su menor precio y gran demanda.

\section{Tráfico restringido del cacao de Guayaquil}

Luego de la ocupación de La Habana y Manila por parte de Gran Bretaña, Carlos III decidió implantar las primeras reformas comerciales con el propósito de estimular los intercambios, legalizar los que se realizaban de manera ilícita e incrementar los recursos fiscales para fortalecer la estructu- 
ra defensiva de Hispanoamérica. José de Campillo y Cosío, quien fue ministro de Hacienda, Guerra, Marina e Indias de Felipe V, de 1741 a 1743 , en su Nuevo sistema de gobierno económico para la América había formulado un programa para impulsar la economía de la metrópoli mediante la transformación de las colonias en consumidoras de las manufacturas españolas y abastecedoras de los cultivos de la agricultura especializada (cacao, azúcar, tabaco, algodón, etc.). Con el fin de que la población de "medianas conveniencias" dispusiera de circulante para adquirir las manufacturas de la Península, sugirió distribuir la tierra y promover el cultivo de los bienes agrícolas más demandados por los mercados europeos (Campillo y Cossío, 1992). Unas décadas después, Pedro Rodríguez Campomanes (1988, pp. 341-348, 386), ministro de Hacienda y gobernador del Consejo de Castilla durante el reinado de Carlos III, en sus Reflexiones sobre el comercio español a Indias propuso establecer "la libertad absoluta de comerciar a toda la nación", por considerar que los monopolios, el sistema de flotas, los trámites burocráticos y los altos gravámenes causaban la decadencia del comercio español y el contrabando. Sin embargo, con el fin de evitar la confrontación con los consulados de Andalucía, México y Perú, las reformas comerciales se aplicaron de manera limitada y paulatina.

160 En enero de 1774 se autorizó a los reinos del Perú, Nueva España, Guatemala y Nueva Granada a intercambiar los efectos y frutos de sus respectivas tierras por los puertos del Pacífico. Para no afectar los intereses de los mercaderes del Consulado de México, en Nueva España únicamente se habilitó Acapulco. La apertura del tráfico interamericano por la mar del sur se limitó básicamente a las materias primas, entre las que se hizo mención expresa al cacao de Guayaquil, 
pero se mantuvo la "absoluta prohibición" de comerciar "vinos, aguardientes, vinagre, aceite de oliva, aceitunas, pasas y almendras" para evitar la competencia con la agroindustria española. Con el fin de proteger los géneros peninsulares, se reiteró la proscripción de embarcar de Nueva España y Guatemala a Perú mercaderías de Europa y Oriente. Y para estimular la producción y el comercio de los bienes de la agricultura especializada se disminuyeron los derechos portuarios, los que gravaban la extracción de mercancías pasaron del 5 al 2.5\% y los de introducción, del 7 al 5\%, de modo que la tasa impuesta al comercio interamericano pasó del $12 \mathrm{al}$ $7.5 \%\left(\mathrm{AGN}, \mathrm{v}^{104}\right)$.

La liberación restringida del comercio por el Pacífico en 1774 favoreció de manera particular el tráfico del cacao ecuatoriano. A partir de entonces, los peruanos remitieron el grano a Acapulco y a otros núcleos mercantiles de la mar del sur directamente desde Guayaquil, valiéndose de sus agentes en dicho puerto. Como consecuencia del establecimiento del comercio directo entre Guayaquil y Acapulco, en 1775 las exportaciones del fruto al Callao descendieron en un $70 \%$ (Contreras Carranza, 1987, pp. 34, 55, 69-71, 167-169). Los cambios institucionales regularizaron el abasto del grano, que en los años anteriores había sido incierto. En 1773, el almacenero Francisco Ignacio de Yraeta se había quejado con un comerciante de Lima del desabasto que se padecía del grano ecuatoriano porque el que le habían enviado se había quedado en Guatemala (Torales Pacheco, 1985, t. II, pp. 194-196). Además, la expansión de las compras del cacao de Guayaquil, que se utilizaba para la elaboración de chocolate, favoreció el incremento de la demanda y el precio del azúcar. Este fenómeno condujo a los mercaderes de México a comprar grandes haciendas para la producción del dulce y 
a destinar mayores inversiones en mejorar la infraestructura que ya tenían (Valle Pavón, 2010a).

La apertura comercial del Pacífico generó la movilidad de los comerciantes que traficaban en Hispanoamérica. Unos meses después de que se dictó la reglamentación mencionada, los hermanos Isidro Antonio, Martín y Nicolás Francisco de Icaza, quienes se dedicaban al comercio en Tierra Firme, pasaron a residir al puerto de Guayaquil, en donde radicaba José Gabriel, otro de los hermanos, que era doctor en derecho y en 1774 había sido nombrado teniente de gobernador y auditor de guerra (Estrada Ycaza, 1973, p. 226; Pinal-Icaza, 1995, p. 878). Los Icaza contrataban añil de Realejo y Sonsonate, cacao ecuatoriano y otras mercancías en Guayaquil, el Callao y Acapulco (Soler Lizarazo, 2010, pp. 132-135). Es muy probable que el tráfico que realizaban los Icaza fuera favorecido por los vínculos políticos que había establecido José Gabriel. Acerca de los medios de que se valía Isidro Antonio de Ycaza para realizar dicho comercio, sabemos que en 1778 obtuvo un préstamo por 22,050 pesos de Isidro Abarca, conde de San Isidro, destacado mercader y financiero que comerciaba al por mayor entre Cádiz, Lima y México y tenía estrechos vínculos con los comerciantes de cacao (Soler Lizarazo, 2010, p. 77)

162 Las autoridades reales estaban convencidas de la necesidad de impulsar el tráfico de los bienes agrícolas en Hispanoamérica, entre los que destacaba el cacao ecuatoriano, por lo que en 1776 concedieron a la provincia de Guayaquil la rebaja a la mitad de los gravámenes que se pagaban a la salida de sus puertos y a la entrada en cualquiera de "ambas Américas". De este modo, los derechos que se imponían al grano cuando ingresaba en Acapulco se redujeron al 2.5\% (AGN, CV 121), 
hecho que lo consolidó como el más barato en Nueva España y favoreció notablemente la demanda. En febrero de 1778, Francisco Ignacio de Yraeta comentó sobre la abundancia de cacao que había en la ciudad de México, cuando acababan de arribar más cargas a Acapulco y estaban "proveídos todos los lugares de este reino y así, aunque no venga barco en dos o tres años, no hará falta..." (Soler Lizarazo, 2010).

El suministro abundante del cacao guayaquileño dio a los mercaderes de la ciudad de México la posibilidad de sustituir un grano por otro, circunstancia que los fortaleció frente a los comerciantes de Caracas. En 1778, el consulado de México informó que entre 1774 y 1778 , el precio de la libra del cacao de Guayaquil había fluctuado entre 1 real y 13/4 real, mientras que el de Caracas había oscilado entre 3 y 4 reales, y sostuvo que los navieros que conducían el cacao caraqueńo a Veracruz habían recurrido a la estrategia de retrasar su envío para elevar su precio a cuatro reales (AGN, CV 121). Sin embargo, en esta ocasión la presión ejercida por los navieros de Caracas para aumentar el precio del grano que comercializaban no tuvo el efecto que buscaban, debido a que los mercaderes de México contaban con grandes existencias del ecuatoriano.

En 1777, el intendente de Caracas elevó a Carlos III una representación en la que expuso la ruina que padecía dicha provincia debido a que en Nueva España los cacaos de Caracas y Maracaibo habían sido desplazados por el de Guayaquil, que entraba por Acapulco en grandes cantidades y a precios bajos a causa de la disminución de derechos. Entonces el grano caraqueño a su entrada por Veracruz tenía que contribuir con el 5\% de almojarifazgo, mientras que el guayaquileño solo pagaba el $2.5 \%$ en Acapulco, además, ambos eran gra- 
vados con los derechos de avería, armada y alcabala. Con el propósito de que se resolviera dicha situación, el intendente hizo tres peticiones alternativas: que se prohibiera el comercio del fruto de Ecuador en Nueva Espańa; que se redujeran los gravámenes que se imponían al cacao de Caracas en Veracruz; o que se extendiera a los caraqueños la libertad de comercio como se había hecho en Guayaquil. El intendente puso énfasis en la necesidad de robustecer la economía de Caracas, provincia que por su ubicación padecía el acoso de las colonias enemigas y podía ser invadida si se desataba un conflicto bélico, amenaza a la que no estaba expuesto Guayaquil (AGN, CV 121). Sin embargo, el monopolio que tenía la Real Compañía Guipuzcoana sobre la comercialización del cacao de Venezuela en la metrópoli constituía un serio obstáculo para desregular el tráfico de los granos de Caracas y Maracaibo.

Las demandas del intendente dieron lugar a que el soberano mandara al virrey de Nueva España que averiguara sobre el asunto, con la intención de restringir el suministro del cacao guayaquileño o igualar los derechos que pagaba en Acapulco con los que contribuían los granos venezolanos en Veracruz. En 1778, Antonio María de Bucareli solicitó informes al consulado y a los principales oficiales de la real Hacienda sobre la situación del tráfico cacaotero con las provincias

164 de Caracas y Guayaquil. En su reporte, el cuerpo mercantil sostuvo que el cacao era uno de los alimentos de primera necesidad para la población de escasos recursos, por lo que la autoridad debía poner especial cuidado en garantizar su abundancia y precio bajo. Planteó que si se prohibiera la contratación del grano guayaquileño habría gran escasez y el reino quedaría a expensas del "odiosísimo" estanco de los caraqueńos, quienes antes de 1774 habían impuesto precios 
intolerables. Y demandó que se aumentara el suministro de dicho cacao para satisfacer la necesidad de la población creciente, dado no sería justo restringirlo por atender a la provincia de Caracas (AGN, CV 121).

$\mathrm{Al}$ no haber visto satisfechas sus demandas, en el mismo año, el intendente de Caracas con el apoyo del ayuntamiento de esa ciudad y de los navieros de la "carrera de Veracruz" reiteró al monarca sus demandas relativas a la disminución de los gravámenes que recaían sobre el cacao venezolano y la extensión del librecambio a la provincia de Caracas. Carlos III tomó una determinación en noviembre de 1778 e impuso a la entrada del cacao de Guayaquil por Acapulco un límite de 8 a 10 mil fanegas anuales con el propósito de favorecer el comercio de los granos de Caracas y Maracaibo (AGN, CV 121: 193-194v). Entonces, los oficiales reales del puerto de Acapulco, que tenían estrechos vínculos con los mercaderes de México, solicitaron al virrey que el peso de la fanega del grano guayaquileño se elevara de 81 a 110 libras, medida que se utilizaba para el fruto de Caracas en Veracruz. Al parecer, dicha medida fue introducida luego de ser aprobada por el fiscal de Nueva España (AGN, CV 121: 195-197v). De esta forma, los mercaderes de México se valieron del cuerpo mercantil y de sus redes clientelares para contrarrestar la medida que pretendía restringir el suministro del cacao de Guayaquil en beneficio de los productores y comerciantes de los granos venezolanos.

En febrero de 1778 Francisco Ignacio de Yraeta, quien había ampliado las contrataciones del grano ecuatoriano, escribió a Lima al mercader de origen vizcaíno Domingo Larrea y Ames sobre la demanda de los cosecheros de Caracas y le pidió que los limeños presionaran ante la corte real para que 
no se impusieran restricciones al grano guayaquileño y se autorizara el tráfico de aceite, aguardiente, almendras y otros productos locales. Los vínculos de Yraeta con otros mercaderes de origen vizcaíno le brindaban la confianza necesaria para comerciar los bienes de la agricultura especializada que se producían en espacios muy distantes de manera global. Domingo Larrea y Ames remitía a Yraeta el fruto ecuatoriano a través de Bernardo Roca Liceras, uno de los grandes monopolizadores del puerto del Guayas (Soler Lizarazo, 2010, pp. 42-43). En contrapartida, Yraeta enviaba a Larrea plata en moneda, añil y grana, tanto a Lima como a Cádiz, dependiendo de las instrucciones que le girara. A inicios de 1778 pidió a José Fernández Gil, su socio en Guatemala, que expidiera añil a Lima a nombre del comerciante Reymundo Marres, quien lo había solicitado para despacharlo a Cádiz. Marres pagó el añil a Yraeta con el envío de cacao de Guayaquil rumbo a Acapulco. Marres envió el tinte guatemalteco a Cádiz. En 1778, Yraeta también remitió añil a Valparaíso con destino final a Santiago de Chile (Soler Lizarazo, 2014, p. 33-34).

\section{Apertura comercial durante la guerra contra Gran Bretaña}

En junio de 1779, poco después de que Carlos III declaró la

166 guerra a Gran Bretaña, la audiencia gobernadora localizó una real orden que autorizaba el comercio de seda china durante los conflictos bélicos para evitar que se padeciera escasez y disminuyeran los ingresos del erario a causa de los bloqueos en el Atlántico. Francisco Xavier Gamboa, uno de los oidores de la audiencia que años atrás había sido consultor y diputado del Consulado de México, dedujo de dicho mandato que se podía permitir la entrada de "todos los cacaos sin limita- 
ción alguna" (Valle Pavón, 2007, pp. 985-995, 998-1003). En consecuencia, el 19 de agosto de 1779 se ordenó a los oficiales reales del puerto de Acapulco que no restringieran el ingreso del fruto ecuatoriano e informaran a los vecinos de Guayaquil sobre la nueva franquicia (AGN, CV 121). En esta decisión pudieron haber influido los mercaderes que trataban grandes cantidades de cacao y azúcar, como José Martín Chávez, dueño de una plantación de azúcar ubicada en Cuautla de Amilpas, que entonces era cónsul del tribunal mercantil, y Francisco Bazo Ibáńez, que había desempeñado el mismo ministerio en el bienio 1773-1774 y cuyo pariente Antonio Ibánez era propietario de una hacienda azucarera en Cuernavaca (Valle Pavón, 2010a).

La guerra también favoreció el tráfico del cacao guayaquileño por otras razones. Francisco Ignacio de Yraeta incrementó sus inversiones en dicho comercio, luego de que en octubre de 1779 los ingleses asaltaron el castillo de San Fernando, en el puerto de Omoa, y capturaron tres navíos españoles, en uno de los cuales había 20 zurrones de añil (García Díaz, 1985, pp. 220, 262, 264). A partir de entonces, Yraeta redujo su participación en la contratación del tinte de Guatemala y empezó a promover el fruto guayaquileño entre los comerciantes del virreinato, de otras posesiones hispanoamericanas y de la metrópoli. Es posible que entonces se estrechara su relación comercial con Isidro Antonio de Icaza, quien, como vimos, compraba el grano en Guayaquil para venderlo en Acapulco.

En mayo de 1779, Isidro Antonio de Icaza arribó al puerto de Acapulco a cargo de una fragata perulera cargada de cacao ecuatoriano (AGN, CV 121: 195v). Es posible que luego de informarse de la liberación total de la introducción de dicho fruto por Acapulco a causa de la guerra, se estableciera en 
la ciudad de México a fin de negociar su venta en cantidades crecientes. Icaza e Yraeta, quienes se identificaban por su ascendencia vizcaína, empezaron a colaborar para vender el grano ecuatoriano en Nueva España. En enero de 1780, Isidro Antonio se valió de su hermano Martín, quien entonces habitaba en la Ciudad de los Reyes, para que se dirigiera al puerto de Guayaquil a comprar grandes cantidades del fruto, realizar cobranzas y otros asuntos vinculados con sus negocios (AHNCM, Notaría 319, v. 2162).

En mayo de 1780, Martín se encontraba en la ciudad de México, en donde, junto con Isidro Antonio, y en nombre del resto de sus hermanos, otorgaron un poder a un primo de Bilbao y a dos procuradores en las villas de Valladolid y Madrid para que probaran su hidalguía a fin de poder obtener honores reservados a la nobleza (AHNCM, Notaría 350, v. 2308). Una vez que los Icaza habían empezado a acumular riqueza, se esforzaban por elevarse en la jerarquía social a fin de vincularse de manera más estrecha con los miembros de las oligarquías de México, Guayaquil y Perú. Además, el testimonio de hidalguía les daría acceso a los gobiernos municipales de las ciudades donde residían, lo que mejoraría su reputación y les permitiría incidir en la política local para impulsar sus negocios. Es posible que los Icaza hayan decidido obtener testimonio de hidalguía por recomendación de

168 Francisco Ignacio de Yraeta, quien había participado en el Ayuntamiento de México como alcalde ordinario de segundo voto, en 1773-1774, y había sido regidor honorario en 1777-1778, al igual que otros destacados miembros del consulado. Así, podemos comprobar cómo en la configuración de las redes de negocios, la familia patriarcal, las lealtades de parentesco y paisanaje resultaban cruciales para el ascenso social y el prestigio de los grandes mercaderes. 
En mayo de 1779, unas semanas antes de declarar la guerra a Gran Bretańa, Carlos III, consciente de que la amenaza de los enemigos limitaría las expediciones por el Atlántico, había facultado al comercio de Filipinas para enviar a Hispanoamérica en navíos de registro "todas las ropas y mercaderías de China que pudiesen”. Con esta medida el rey aseguró el abasto y los ingresos del erario (AGN, RC 117-96). A partir de entonces, los navíos de registro procedentes de Manila pudieron vender géneros asiáticos en Acapulco, Guayaquil y el Callao, y adquirir cacao de Guayaquil para negociarlo a su regreso en el mencionado puerto novohispano. También podían comerciar los bienes asiáticos en los puertos de Arica, Valparaíso y La Concepción. En agosto de 1779 el ministro de Indias, José de Gálvez, informó al virrey de Nueva España sobre la disposición real para que se permitiera el desembarco en Acapulco a los navíos procedentes del archipiélago y se les cobraran los mismos derechos que al galeón de Manila (AGN, RC 117-94). De acuerdo con el mercader Francisco Ignacio de Yraeta, la medida tuvo efecto poco más de un año después, a partir de septiembre de 1780 (Torales Pacheco, 1985, t. II, p. 69).

Los bloqueos y la efectividad de los corsarios británicos redujeron al mínimo el comercio de las posesiones hispanoamericanas con la Península al inicio de 1780. En los espacios del Pacífico meridional empezaron a escasear los textiles europeos y su precio tendió a elevarse, lo que hizo su venta sumamente rentable. En 1780 arribaron al Callao dos navíos con cargamentos asiáticos procedentes de Acapulco, uno de ellos llevaba efectos de Castilla, parte de los cuales fueron comisados, lo que muestra que se había iniciado dicho tráfico de manera ilícita. Cuando estalló la guerra, el navío Hércules de la compañía vasco-navarra Ustáriz y San Ginés establecida 
en Cádiz, se encontraba en Manila. Dicha embarcación viajó a Cantón para adquirir géneros de seda y algodón, especias y otros bienes, parte de los cuales se vendieron en Acapulco en 1781, el resto se intercambiaron en Guayaquil y el Callao por plata andina y cacao. Al parecer, el Hércules hizo otra expedición al Oriente, ya que en 1782 fue registrado en Acapulco con destino a Guayaquil y el Callao, de donde regresó en 1783 (Ruiz Rivera, 1976, pp. 188-192).

A mediados de 1779, el soberano también había otorgado licencia a la compañía Ustáriz, San Ginés para comprar mercancías asiáticas y negociarlas en los puertos del Pacífico hispanoamericano por la ruta del Cabo de Hornos (Ruiz Rivera, 1976, pp. 188-192). Dicho comercio tenía sus antecedentes en los esfuerzos de la Corona por abrir el tráfico directo entre España y Filipinas con el doble objeto de fomentar la economía productiva del archipiélago y disminuir la importancia del comercio monopólico que realizaba la Nao de China. Es poco probable que durante la guerra se utilizara la vía del Cabo de Hornos, luego de que en octubre de 1779 una de las embarcaciones de la compañía Ustáriz y San Ginés, que había viajado con licencia al Callao por la ruta mencionada, a su regreso a España había sido apresada por los ingleses cerca de las islas Azores (Lamikiz, 2010, pp. 371-372). No obstante, en julio de 1780 el Consulado de Lima, en representación

170 de los dueños de embarcaciones del tráfico de los puertos del Mar del Sur, pidió al rey que no concediera licencia alguna a los navíos de registro de Espańa para traficar en ellos los frutos y producciones del País (Bonialian, 2012, pp. 417, 418). Es muy posible que esta solicitud fuera planteada luego de conocer la autorización que el rey había dado para que se comerciaran bienes asiáticos desde Manila con los puertos de la mar del sur. 
El intercambio de mercancías orientales y novohispanas por cacao ecuatoriano debió haber sido tan redituable, que Isidro Antonio de Icaza llamó a México a su hermano, José Gabriel, quien había sido abogado de las Reales Audiencias de Santa Fe y Quito. En enero de 1781 José Gabriel y su familia arribaron a Acapulco en un navío cargado de cacao procedente de Guayaquil. El recién llegado poseía un capital considerable producto de su trabajo, de la dote de su esposa, que era natural de Guayaquil, y de la herencia que esta había recibido de una tía que había muerto en Lima (Espinoza de los Monteros, 2008, pp. 84-85; García Díaz 1985, pp. 258259, 261). Presumimos que José Gabriel invirtió su capital en las redituables contrataciones del fruto ecuatoriano. Es probable que la elevada rentabilidad del tráfico del cacao se debiera a que era intercambiado por textiles asiáticos y europeos de manera subrepticia, dado que Yraeta podía contar con la complicidad de las autoridades de Acapulco con las que tenía estrechos vínculos, ya que desde décadas atrás participaba en el comercio del galeón de Manila. Los negocios de los Icaza se fueron consolidando luego de que su hermano Martín de Icaza fue electo procurador del cabildo de Guayaquil en 1781 y alcalde ordinario en 1782. Martín, además de dedicarse al comercio, prestaba dinero a réditos, en algunos casos para pagarse en el puerto de Acapulco (Soler Lizarazo, 2010). Al parecer, en esta época Martín Icaza empezó a comprar tierras para plantar cacao con los caudales acumulados de las contrataciones comerciales que realizaba y el otorgamiento de créditos.

En abril de 1781 el virrey Martín de Mayorga solicitó, en nombre del monarca, un donativo universal para contribuir con las urgencias de la guerra anglo-española y comisionó al consulado para recoger las contribuciones de los comer- 
ciantes que eran vecinos de la ciudad de México y de los que residían en ella de manera temporal. Entre estos últimos se encontraban treinta y dos flotistas que donaron en total 1201 pesos y 309 comerciantes de China, cuyo donativo ascendió a 4,500 pesos. Asimismo, se encontraban los comisionados de los cinco gremios mayores de Madrid y algunos comerciantes peruanos (AGN, Consulado 2217-17). Entonces, debió haberse presentado una gran competencia en la ciudad de México, en la que los mercaderes consulares tenían la ventaja de disponer de la solvencia necesaria para realizar ventas a crédito.

La correspondencia de Francisco Ignacio de Yraeta a la que tuvo acceso Stanley Stein lo llevó a concluir que "el gran éxito comercial de Yraeta ocurrió en 1781”. El mercader manifestó a uno de sus corresponsales que en marzo de ese año había hecho una importante negociación al adquirir un gran lote de textiles chinos finos. En julio, informó a su agente en Madrid que en Nueva España había "muchos caudales de España, Filipinas y aún de Lima, y que para fin de año se esperaba embarcación de Guayaquil y la nao de Filipinas", lo que le abriría mayores oportunidades. Además, hizo un balance positivo de las "negociaciones de China" que había realizado en 1780, cuando había contratado bienes orientales por valor de 300,338 pesos y en los seis meses que habían transcurrido

172 de 1781 había adquirido mercancías asiáticas por 200,000 pesos (Stein, 2001, pp. 473-474). En 1780, ante la amenaza de los británicos que habían tomado Manila, los filipinos habían sido autorizados a subir a México a vender con plena libertad, por lo que habían sobrecargado los precios de sus mercancías de manera exagerada. Las cifras sobre las negociaciones que efectuó Yraeta en los años de guerra resultan impresionantes, sobre todo si las comparamos con las tran- 
sacciones que había llevado a cabo en 1779, cuando había negociado en Acapulco cerca de 200,000 pesos, gran parte de los cuales había recibido por comisión de mercaderes de Guatemala y en menor medida del interior de Nueva España (Yuste, 1985, pp. 285-286). Yraeta contrataba gran parte de los bienes asiáticos en Guayaquil y Lima con sus corresponsales y a través de Isidro Antonio de Icaza, con quien se vinculó cada vez de manera más estrecha.

\section{Intercambio de géneros de Asia y Europa por cacao y plata andina}

A fines de 1781, Isidro Antonio de Icaza formó compañía con Damián de Arteta, el apoderado del comercio de Guayaquil para comercializar efectos asiáticos y europeos en el Callao (Soler Lizarazo, 2010). En noviembre Isidro Antonio de Icaza, registrado como comerciante de Perú, solicitó al virrey Martín de Mayorga que declarara que por ahora "no había embarazo para extraer por el puerto de Acapulco géneros de Castilla y China”. Presumimos que Icaza había comprado importantes lotes de dichos textiles, porque unos días antes, junto con su hermano José Gabriel, había conseguido que el riojano Francisco Bazo Ibánez, a quien vendían cacao desde años atrás, les otorgara un préstamo por 51,250 pesos, "solo con el fin de hacerles amistad, favor, y buena obra", leyenda que solía ocultar el cobro de una tasa de interés superior al 5\%, que era la autorizada por el derecho canónico. En garantía, los Icaza obligaron "su persona y bienes habidos y por haber", sin presentar fiador, ni hipoteca especial. El crédito se estableció por un periodo de seis meses, el cual debió haber sido renegociado, dado que el dinero se reembolsó en noviembre de 1782, cuando había transcurrido un año (AGNCM, Not. 350 v. 2309). 
Por su parte, Damián de Arteta, en diciembre del mismo año de 1781, obtuvo de Francisco Ignacio de Yraeta un préstamo por 104,000 pesos, para "la habilitación y costos de la negociación" del navío La Aurora que llegaría en los próximos días al puerto de Acapulco cargada de cacao de Guayaquil. El crédito fue garantizado con "los fondos de la enunciada negociación”, por lo que se precisó que con los productos que generara Arteta no podría pagar a ningún otro individuo. En lugar de precisar la tasa de réditos que se impondría por dicha obligación, también se anotó la leyenda "sólo con el fin de hacerle amistad y buena obra” y se estableció un plazo de ocho meses para la restitución del capital (AHNCM, Notario 350, v. 2309). El otorgamiento de este préstamo parece indicar que Yraeta también estaba involucrado en el tráfico de géneros extranjeros que Icaza y Arteta pretendían realizar por el mar del sur.

Como se retrasaba la resolución de Martín de Mayorga sobre el comercio de tejidos asiáticos y europeos por el Pacífico, debido a que se tenía que conceder la "dispensa o franquicia general" sobre el asunto, en diciembre Icaza y Arteta le manifestaron la urgencia que tenían de embarcar los efectos que habían adquirido. Al cabo de unos días, el virrey les concedió la licencia, sin perjuicio de la decisión que se tomara acerca de "la providencia general" (AGN, IV 2223-19). De modo

174 que otros navíos que partieron rumbo a los puertos meridionales del mar del sur, en febrero de 1782, cuyas cargas sumaban aproximadamente 230,000 pesos, pudieron haber transportado lienzos orientales y europeos de manera subrepticia (Bonialian 2012, pp. 430).

Martín de Mayorga pudo haber concedido a Icaza y Arteta la licencia para comerciar efectos extranjeros por el Pacífico, a 
petición de Yraeta, quien cultivaba la relación interpersonal con los virreyes (Torales Pacheco, 1985a, pp. 55-58). También debe tenerse en cuenta que al inicio de 1782 el virrey enfrentaba el problema de carecer de fondos para satisfacer las necesidades que las fuerzas armadas que luchaban contra los ingleses padecían en La Habana, por lo que en febrero solicitó a los principales mercaderes de México suplementos o préstamos a corto plazo sin interés. Mayorga supuso que no habría problema en obtener dichos caudales porque el bloqueo del Atlántico había suspendido el tráfico con la metrópoli. Es posible que el virrey hubiera otorgado a Icaza la mencionada licencia pensando en el apoyo financiero que podría otorgarle su socio Francisco Ignacio de Yraeta, quien suplió al virrey 40,000 pesos, lo que lo situó en el décimo lugar de los contribuyentes (Valle Pavón, 2015, pp. 152-153). De esta forma, los almaceneros que se ubicaban en la cúspide de la jerarquía del comercio de México lograron que Mayorga hiciera extensivas a Nueva España las concesiones mercantiles que el soberano había otorgado en otros espacios.

A principios de febrero de 1782, Isidro Antonio de Icaza consolidó su relación con Francisco Ignacio de Yraeta al contraer matrimonio con su primogénita. En el documento que formalizó la dote de María Rosa de Yraeta, Icaza hizo "prudente cálculo" del importe de su caudal, el cual estimó de manera "bien moderada" en 88,000 pesos, los cuales estaban repartidos en sus comercios en Guayaquil, Lima, Guatemala, Oaxaca y México (AGNCM, Not. 350, v. 2310). Para Icaza fue sumamente relevante pasar a formar parte de la familia de Francisco Ignacio de Yraeta, quien tenía estrechas relaciones interpersonales con las principales autoridades del virreinato y había tejido sólidas redes con comerciantes en diversos espacios de Hispanoamérica y la metrópoli. 
En abril de 1782, Isidro Antonio de Icaza encontró la vía más adecuada para recibir el pago en efectivo de parte de los géneros que había remitido al Perú. Debido a la amenaza de los británicos no se había podido remitir a Nueva España azogue de Almadén, por lo que el virrey decidió comprar 4000 quintales del de Huancavelica, cuyo valor ascendía a 143,000 pesos. Isidro Antonio propuso a Mayorga que para evitar los riesgos y el costo del envío del dinero, le entregara 100,000 pesos a cambio de los cuales le daría una libranza a favor de la tesorería del virreinato peruano, la cual sería pagada por los comerciantes de Lima con los que tenía mayores tratos: los hermanos Antonio y José de Elizalde o Antonio López de Escudero. El mercader propuso afianzar los 100,000 pesos con el aval de su padre Francisco Ignacio de Yraeta y, en caso de ser necesario, de algún otro vecino de igual crédito y caudal. Mayorga aceptó la propuesta, pero, de acuerdo con el dictamen del fiscal Ramón Posada, resolvió satisfacer la cantidad librada hasta asegurarse de que el dinero se hubiera depositado en las arcas del erario de Lima. A principios de septiembre, los oficiales de la Real Caja de la Ciudad de Los Reyes informaron al virrey que habían recibido los 100,000 pesos en plata. En diciembre llegaron a México los 4000 quintales de mercurio, por lo que Icaza recibió los 100,000 pesos en cuestión. ${ }^{5}$ Así, los vínculos que tenía Yraeta con las autoridades virreinales le dieron acceso a información privilegiada sobre las compras de azogue que se realizarían en Perú, lo que permitió a Icaza recibir gran parte de la plata con la que le

5 AGN, AHH 8, v. 204, exp. 18 y 29. El navío "San Pablo" llegó a Acapulco con una carga por valor de 315,270 pesos, de los cuales 143,300 pesos correspondían al valor de 4000 quintales de azogue y los restantes 171,970 pesos al cacao de Guayaquil y otros bienes andinos (Bonialian, 2012, pp. 429-431). 
pagaron los efectos que había enviado al Callao, sin tener que erogar los costos de transporte ni el seguro marítimo.

A principios de 1782, Martín de Mayorga había solicitado el parecer de varias autoridades y del tribunal del Consulado sobre la posible "dispensa o franquicia general" para contratar efectos de Europa y China en el Perú. Para responder, el tribunal y audiencia de cuentas tuvo presente que en junio de 1780 el soberano había autorizado al virrey de Nueva Granada para que sus habitantes, entre los que se encontraban los de la provincial de Guayaquil, pudieran intercambiar "los frutos y géneros de su cosecha por bienes europeos en todos los puertos españoles de América”, con el propósito de resolver la carestía que el bloqueo por parte de los ingleses había generado en Venezuela (AGN, IV 2223-19). Dicho tribunal consideró que las licencias que se habían otorgado a Isidro Antonio de Icaza y Damián Arteta eran conformes con la concesión que había otorgado Carlos III a los súbditos de Nueva Granada, aun cuando la orden dirigida al virrey de Santa Fe no se hubiera comunicado al de Nueva España, dado que en épocas de guerra se otorgaban este tipo de licencias para evitar que los reinos americanos carecieran de efectos de subsistencia (AGN, IV 2223-19).

El tribunal del Consulado consideró que la real cédula que había autorizado a los vecinos de Nueva Granada el comercio de bienes europeos durante el conflicto bélico no se había hecho extensiva a Nueva España, porque el envío de dichos efectos al Perú perjudicaría a los cargadores peninsulares que abastecían a dicho virreinato, al ocasionar la baja de precios. Y recordó que por esta razón se había prohibido el comercio recíproco entre ambos virreinatos. Planteó que si la orden dada para Santa Fe se hiciera extensiva a Nueva España de 
manera absoluta y sin restricción alguna, "llegará el caso de que por socorrer la necesidad de aquel reino" se generaría la misma escasez en este y el consiguiente aumento de precios, por lo que se debía limitar la facultad de extracción a "los efectos que abundaran". Con este fin propuso que las licencias que se otorgaran a Icaza, Arteta y otros pretendientes, se condicionaran a que rindieran un informe para dicho tribunal, en el que presentaran las facturas con "los rubros, clases y cantidades de los efectos que solicitan extraer" con el propósito de que determinara si se podía conceder el permiso en cuestión "en el todo o en parte” (AGN, IV 2223-19).

Poco después, el comerciante peruano José Joaquín de Hornaza pidió la misma licencia que se había concedido a Icaza y Arteta, pero la real Hacienda, teniendo en cuenta los argumentos que había dado el consulado, dictaminó que se le negara. No obstante, consideró que podía permitirse la extracción de las mercaderías chinas a Perú, teniendo en cuenta, primero, que el soberano había autorizado a los comerciantes de Filipinas a embarcarlas rumbo a Hispanoamérica para que no decayera el comercio, ni los ingresos del erario; segundo, que dicho mandato también se había girado al virrey de Nueva España, además de haberse reiterado en abril y junio de 1781; y tercero, que la extracción de los géneros orientales a Perú no perjudicaba a Castilla, dado que las comunicaciones por el Atlántico 178 estaban interrumpidas (AGN, IV 2223-19). Por su parte, el fiscal Ramón Posada admitió que estaba permitido el comercio de textiles chinos únicamente "durante la guerra y pagándose los derechos reales” (Rodríguez García, 1985, p. 53).

El asesor general de la Real Audiencia consideró que ante la escasez del comercio y de los ingresos reales que se padecía en el Perú a causa de las dificultades que enfrentaban los pe- 
ninsulares para llegar al Callao, los mercaderes de México podían vender las telas que abundaban y tenían rezagados, para lo cual se requería el dictamen del consulado. Estas contrataciones favorecerían a los erarios de ambos reinos, porque dichas mercancías pagarían los derechos de almojarifazgo, así como de extracción e introducción en los puertos (AGN, IV 2223-19). De acuerdo con el parecer del asesor general, el 27 de abril de 1782 el virrey Mayorga decretó que durante la guerra se podían extraer al Perú "géneros europeos y de China introducidos en Nueva España... entendiéndose única y precisamente de los que abundaren o no escasearen en ella, cuya calificación debería formalizarse por previo informe del real Tribunal del Consulado, a quien se pasarán las solicitudes de los pretendientes acompañadas de las facturas específicas e individuales de los géneros que se querían extraer, para que instruido, como asegura estarlo, de la abundancia o escasez de cada especie, exponga a este Superior Gobierno lo que en el asunto se le ofreciese y pareciese" (AGN, Consulado 49728). Este comercio pagaría los derechos establecidos en el Reglamento de Comercio Libre de 1778 (AGN, IV 2223-19).

En junio de 1782, las autoridades de La Habana volvieron a requerir capitales al virrey para sostener la lucha contra los ingleses. Como el erario carecía de fondos, Mayorga solicitó a los tribunales del consulado y minería que operaran como intermediarios financieros de la hacienda novohispana para reunir dos empréstitos por un millón de pesos cada uno. El mayor depósito que recibió el cuerpo mercantil fue el del almacenero Manuel García Herreros por 230,000 pesos, cantidad gigantesca con la que se podía comprar una hacienda de grandes dimensiones o construir un navío de guerra de ochenta cañones. En enero de 1783, García Herreros pediría al tribunal mercantil licencia para comerciar efectos de 
Oriente y Europa por el mar del sur, como consignatario de Sebastián de Heras Soto, encomendero peninsular que al inicio de 1782 había hecho un suplemento por 30,000 pesos, junto con otros dos flotistas (Valle Pavón, 2015, pp. 161-164; AGN, IV, v. 4972-8). Manuel García Herreros era sobrino del mercader Francisco Martínez Cabezón, quien estaba fuertemente involucrado en el comercio de bienes orientales y era tratante de cacao desde fines de los años cincuenta. Presumimos que García Herreros depositó en el consulado los 230,000 pesos para el empréstito que se otorgó al rey en agosto de 1782, porque quería influir en el tribunal mercantil y el gobierno a fin de que le dieran autorización para comerciar los efectos extranjeros por Acapulco.

En junio de 1780, Carlos III reiteró la orden de noviembre de 1778 que limitaba la introducción del cacao de Guayaquil por Acapulco a un máximo de ocho a diez mil fanegas, "a fin de que tuviese alguna salida el de Caracas". ${ }^{6}$ A partir de entonces, las autoridades de la metrópoli negaron la mayor parte de las licencias que solicitaron los productores y tratantes del fruto guayaquileño. El fiscal Ramón Posada pidió al gobierno la estricta observancia del mandato real; no obstante, manifestó al ministro de Indias, José de Gálvez, que la libertad del comercio de cacao de Guayaquil no perjudicaba a la provincia de Caracas, que "gemía bajo el pesado yugo" de la Real Compañía

180 Guipuzcoana. Explicó que el grano guayaquileño se vendía mucho en Nueva España, lo cual no impedía que dejara de

6 En la real orden que se dictó el 13 de junio de 1780 también se especificó que las fanegas del cacao que se recibieran por Acapulco debían regularse a 110 libras cada una, como se regulaban las del grano caraqueño que ingresaba por Veracruz (Rodríguez García, 1985, p. 154). Como vimos, esta medida ya se había sido introducida en dicho puerto. 
comprarse el de Caracas y Maracaibo "por ser el más apreciado", mientras que los derechos reales tenían considerables aumentos a la entrada del cacao en Acapulco y por el cobro de la alcabala en el interior del reino (Rodríguez García, 1985, p. 154). Presumimos que esta situación y los fructíferos negocios que realizaban los mercaderes de México pudieron haber conducido al virrey a posponer de manera indefinida la restricción de la entrada del cacao de Guayaquil por Acapulco.

En Guayaquil, la política real no impidió que continuaran enviando el fruto a Nueva España, sobre todo teniendo en cuenta las dificultades que enfrentaban para remitirlo a la metrópoli a causa de la amenaza de los británicos. En dicho año, Isidro Abarca, conde de San Isidro, en sociedad con Ángel Izquierdo y su hermano Joaquín Abarca, remitió a Francisco Ignacio de Yraeta por lo menos 4229 cargas de cacao de Guayaquil, luego de que en 1773 habían dejado de comerciarlo, al parecer, por las dificultades de su carácter perecedero y su precio inestable. ${ }^{7}$ En 1781 y $1782 \mathrm{el} \mathrm{conde}$ de San Isidro, en sociedad con Ángel Izquierdo y con su hermano Joaquín Abarca, prosiguió remitiendo a Yraeta cacao a consignación para que enviara el producto de su venta a Cádiz (Flores, 1999, p. 106; Soler Lizarazo, 2010, pp. 85, 226).

El arribo de crecientes cantidades del grano guayaquileño condujo a la reducción de su precio, no obstante, siguió ingresando por Acapulco en grandes cantidades, siendo Isidro Antonio de Icaza uno de los principales introductores (Soler Lizarazo, 2010, p. 228). En diciembre de 1781, Yraeta escri-

7 Yraeta había realizado negocios con Isidro Abarca luego de que este había operado con su suegro Pedro de Ganuza durante varios años (Soler Lizarazo, 2010, pp. 78-81, 93, 226). 
bió a su corresponsal en Veracruz que la restricción a la entrada del fruto de Guayaquil no había tenido efecto porque de dicho puerto habían remitido al de Acapulco "todas las porciones que han podido en barquitos pequeños" que arribaban todos los días (Torales Pacheco 1985, t. II, p. 240). En marzo de 1782, Yraeta informó al conde de San Isidro sobre el cacao ecuatoriano que le había enviado en consignación, que debido a la abundancia de las remisiones de 1781 no había "tomado mucha estimación, pues don Isidro Antonio Icaza y don Damián de Arteta, [...] no quieren vender sobre los precios a que les han ofrecido los vecinos, pues no han llegado a real y medio". Agregó que todo el reino estaba bien abastecido y que si continuaban arribando "iguales partidas como estos últimos años, no se podrá sostener" (Torales Pacheco 1985, t. II, pp. 85-86, 229).

Como vimos, Isidro Antonio de Icaza compraba el cacao ecuatoriano valiéndose de su hermano Martín, que había arraigado en Guayaquil, y de mercaderes que se hallaban a la cabeza del Consulado de Lima, como los hermanos Antonio y José Matías de Elizalde (Villa Esteves, 1999, pp. 133-174), que además se lo enviaban a consignación. En 1782 Domingo Ramírez de Arellano, tratante riojano establecido en la ciudad de Lima, remitió una importante carga del fruto guayaquileño al puerto de Acapulco, junto con un poder a nombre de Icaza, de

182 Francisco Bazo Ibáñez -quien también procedía de La Rioja- y de Joaquín Ramírez de Arellano, del comercio de Oaxaca, para que lo expendieran en su nombre (Aguilar Gil, 1999, p. 182). En mayo de 1782, el mercader gaditano Martín Aguirre había mandado a un tratante de Lima comprar en Guayaquil 3000 cajas de cacao para remitirlas a Acapulco a consignación de Yraeta. Este, luego de vender el grano, debía invertir "su producto en grana que le enviaría a Cádiz” (Soler Lizarazo, 2010, 
pp. 70-71). La grana y el añil tenían gran demanda por parte de la industria textil europea y su comercio se facilitaba porque tenía la cualidad de que "no desmerecer aunque se guarde mil años” (Stein, 2001, p. 483).

Mientras que en Nueva España los precios del cacao ecuatoriano se habían desplomado a los niveles más bajos, en Lima se habían incrementado notablemente. En consecuencia, en el mismo mes de mayo de 1782, Yraeta recomendó a uno de sus corresponsales en la Ciudad de Los Reyes que reservara la venta del grano para otro momento. Algunos mercaderes como Manuel Barragán quien, como vimos, desde 1769 vendía el fruto guayaquileńo a Yraeta, optaron por contratarlo en la capital del Perú. En febrero de 1783, Yraeta le comentó que había tomado una buena determinación. En 1784, cuando se elevó el precio del fruto guayaquileño, Barragán volvió a remitirlo a Yraeta (Soler Lizarazo, 2010, pp. 163, 230).

El límite a la introducción del cacao por Acapulco de 8000 a 10,000 arrobas finalmente fue impuesto por el virrey Martín de Mayorga en junio de 1782. A partir de entonces, los oficiales reales de Acapulco negaron los permisos para desembarcar el grano a varios comerciantes, incluido Damián de Arteta, el apoderado de los vecinos de la ciudad y provincia de Guayaquil, lo que generó las protestas del cabildo y los comerciantes de dicha urbe. El descontento de los guayaquileños se exacerbó porque el soberano continuaba otorgando permisos para traficar el cacao a navegantes y súbditos acaudalados, en recompensa por los servicios financieros y materiales que prestaban para solventar las emergencias de la guerra (Arcila Farías, 1975, pp. 293-301). En agosto de dicho año, Damián de Arteta, solicitó al virrey que durante la guerra se suspendiera el cumplimiento del mandato real (AGN, IV 4972-8: 28-30). 
A principios de octubre de 1782, el tribunal del consulado informó al virrey que había reconocido las facturas que había presentado Tomás Pasquel, del comercio de España, que comprendían los efectos que solicitaba transportar al Perú y que no siendo de los que escasean en Nueva España, no encontraban inconveniente en que se le diera el permiso correspondiente (AGN, IV 4972-8: 31-32).

En marzo de 1783 el fiscal de la real Hacienda, Ramón Posada, informó a José de Gálvez que no se cumplían las reales órdenes que limitaban las introducciones del cacao de Guayaquil por Acapulco. Precisó que en enero de 1783 había anclado en dicho puerto la fragata Nuestra Señora de Belén con 2431 cargas de cacao para el consumo del virreinato y 4173 para el de Espańa; poco después había llegado al mismo puerto el navío Santa Ana con cerca de 20,000 cargas del mismo producto. El fiscal había recomendado que se libraran órdenes a los oficiales reales de Acapulco para que luego de hacer cuenta de las fanegas de cacao que se habían introducido de la fragata Nuestra Señora de Belén, no permitieran descargar del Santa Ana mayor cantidad de la que faltaba para completar las 10,000 fanegas correspondientes a dicho año. $Y$ en caso de que se hubiera desembarcado mayor cantidad de la estipulada se volviera a cargar el excedente. Sin embargo, no se atendió su parecer (Rodríguez García, 1985, 184 p. 154). ${ }^{8}$

Como consecuencia de la liberalización del tráfico por el Pacifico y de las licencias otorgadas durante la guerra, se generó

8 En 1783 arribaron a Acapulco el navío Belem con 6000 cargas de cacao, el Santa Ana con 19,000 cargas y el Aurora con 14,500 cargas (Miño Grijalva, 2013, p. 190). 
un notable incremento en las introducciones del grano guayaquileño a Nueva Espańa. De acuerdo con las cifras sobre las introducciones de cacao en Acapulco proporcionadas por Bonialian (2012, pp. 423) y Miño Grijalva (2013, pp. 185186), para el quinquenio 1774-1778 el primero contabilizó 53,714 fanegas de 81 libras, y el segundo 71,378 cargas con el mismo peso, el monto prácticamente se triplicó en el periodo 1779-1783, al pasar a 165,600 fanegas, según el primero y 166,983 cargas, de acuerdo con el segundo.

En febrero de 1783 el consulado manifestó al virrey su preocupación por la situación del comercio de Nueva España. En particular, por la captura del convoy procedente de España que se esperaba en México y los riesgos que padecía el comercio a causa de la guerra, así como por las dimensiones que había adquirido la extracción de efectos asiáticos y europeos, ya que de continuar dicho permiso, empezarían a escasear y su valor ascendería a precios “insoportables". Planteó que "la multitud de pretendientes" que ocurrían a pedir licencias para extraer géneros cada vez que iban a salir buques para el Perú, pronosticaba la "lamentable ruina" del comercio de México. Tan solo en enero y febrero se habían recibido treinta y un solicitudes para realizar dicho comercio. Informó que de mayo de 1782 a febrero de 1783, en escasos nueve meses, se habían exportado al Perú más de 3000 piezas de distintos efectos de Oriente y Europa. Y en nombre de los consumidores que veían aumentar los precios, suplicó al virrey el cese del tráfico con el reino del Perú y, unos días después, pidió que se suspendiera el otorgamiento de licencias hasta que se tomara una determinación (AGN, Consulado 4972-8).

En marzo de 1783 el fiscal de la real Hacienda, Ramón Posada, que estaba vinculado con el Tribunal mercantil, informó 
a José de Gálvez que "a pesar de los pedimentos fiscales, las reflexiones del Consulado y la expresa prohibición real", en 1782 se había embarcado al Perú cuantos textiles europeos y orientales habían querido "con permiso más o menos expreso del superior Gobierno”. Estimó que por los muy considerables beneficios que habían obtenido, en 1783 habían vuelto a comprar grandes cantidades de géneros para embarcarlos al Perú. Entonces iban hacia Acapulco más del 3000 tercios, lo cual se había autorizado únicamente con el dictamen del asesor general de la audiencia, sin haber pedido el parecer del fiscal Posada, por lo que se quejó de que todo se hacía "sin temeridad" con desprecio de las cédulas y órdenes del rey (Rodríguez García, 1985, p. 153)

En el mismo mes de marzo, el virrey solicitó al consulado que convocara a una junta de consejeros y diputados para proporcionar mayor información sobre la situación del comercio de efectos asiáticos y europeos con el Perú, teniendo en cuenta el escrito que había recibido de diez cargadores de Lima y Guayaquil, quienes debieron haber estado preocupados por los rumores de que se iba a prohibir el tráfico de las mercaderías en cuestión. Con respecto a la abundancia de los géneros comprendidos en las facturas que evaluaba el consulado, se planteó que en varios casos no se presentaban las facturas con el desglose necesario para saber si se trataba de

186 mercaderías que abundaban o escaseaban a fin de asegurar el pronto despacho de los permisos. Luego de realizar la junta, el consulado solicitó al virrey que si se resolvía que continuara la extracción de telas, aunque fueran abundantes, los pretendientes deberían presentar facturas en las que precisaran con detalle sus calidades. Informó que desde enero se habían recibido treinta y nueve solicitudes de comerciantes de México, una de un español y otra de un guayaquileño, muchos 
de los cuales habían pedido licencia para extraer gran número de géneros, habiendo comprado solo una cuarta parte, para que en caso de que se cerrara dicho comercio, pudieran vender el permiso a otros. En consecuencia, suplicó al virrey que suspendiera dicho tráfico hasta que llegara el convoy de Cádiz que se esperaba, y que se estableciera que quienes habían obtenido dichas licencias, debían extraer los efectos de la ciudad de México antes del 30 de abril para evitar que vendieran las licencias (AGN, Consulado 4972-8).

Podemos tener una idea de la forma en que los peruanos realizaban este comercio y los montos que traficaban con los siguientes ejemplos. En marzo de 1783 Domingo Ramírez de Arellano, el mencionado mercader riojano vecino de Lima, en sociedad con Juan Bautista Mancisidor y José Molla, adquirieron efectos de Castilla en Acapulco por valor de 36,961 pesos (Aguilar Gil, 1999, p. 182). Es posible que estos bienes se compraran a través de Isidro Antonio de Icaza o Francisco Bazo Ibáńez, quienes, como vimos, en 1782 se habían hecho cargo de vender en nombre del mismo Ramírez Arellano el cacao que les había remitido. Pero lo que es realmente impresionante es que, en 1783, el navío Nuestra Señora de las Mercedes, haya distribuido por los puertos de Paita, Guayaquil y El Callao un total de 204,800 pesos en efectos, de los cuales 151,280 pesos correspondían a géneros extranjeros, 29,790 pesos a asiáticos, 18,340 espańoles y 5,390 pesos a efectos de la tierra (Bonialian, 2012, p. 434). En agosto de 1783 el virrey determinó que de acuerdo con la real cédula de enero de 1774, no se podían extraer al Perú textiles de Europa y Asia "aunque sean abundantes en este Reino y poco gastables en él”, con lo que se suspendió dicho tráfico. 


\section{Conclusiones}

El incremento del tráfico de cacao de Guayaquil que generó la apertura de los principales puertos del Pacífico en 1774 dio lugar a que los hermanos Icaza cambiaran de lugar de residencia con el propósito de tener mayor participación en su comercio. Dado que solo se conoce este caso, habría que realizar mayores investigaciones sobre la movilidad espacial de los mercaderes de origen hispano y cómo propició la integración de los mercados de la mar del sur y de otras colonias hispanoamericanas. El tráfico en los puertos meridionales del Pacífico se le facilitó a Isidro Antonio de Icaza por el hecho de que sus hermanos Martín y Nicolás Francisco Icaza se establecieron en Guayaquil, además de que el primero se dedicó al cultivo del cacao y fue miembro del cabildo.

Tras el establecimiento de la apertura comercial limitada por el Pacífico se incrementaron las introducciones del cacao ecuatoriano por el puerto de Acapulco, lo que generó la reducción de su precio y la consiguiente elevación de la demanda. En adelante, los tratantes de Venezuela no pudieron elevar los precios de los granos de Caracas y Maracaibo. Ante las demandas del intendente de Caracas, que veía limitadas las posibilidades comerciales de la provincia por el monopolio de la Real Compañía Guipuzcoana, el monarca mandó restringir la entrada del grano guayaquileńo por el puerto de Acapulco. No obstante, los mercaderes de la ciudad de México que se dedicaban a la contratación del cacao guayaquileño se valieron de los representantes del consulado y de las relaciones clientelares que tenían con los oficiales reales de Acapulco para conseguir que se elevara el peso de la fanega del grano que entraba por dicho puerto. 
Todo parece indicar que la autorización que otorgó Carlos III a los tratantes de Filipinas para contratar efectos asiáticos en los puertos del Pacífico, en el marco del conflicto bélico, fue aprovechada por los mercaderes que negociaban cacao ecuatoriano para intercambiar de manera ilícita los bienes europeos y orientales que abundaban en México por el cacao y la plata andina. Este comercio podría explicar el aumento que presentó el ingreso del fruto ecuatoriano en Nueva España en especial en 1780 y 1781, cuando no había sido autorizada la reexpedición de dichos efectos a los puertos del Pacífico sur. En este caso, las restricciones establecidas al comercio intercolonial fueron más formales que reales. Las decisiones de las autoridades virreinales y los privilegios que beneficiaron los proyectos empresariales de Yraeta e Icaza fueron posibles, tanto por los vínculos políticos que el primero había cultivado, como por el otorgamiento de donativos y préstamos para financiar las campañas bélicas contra Gran Bretaña. Esta situación no fue exclusiva de los mercaderes mencionados, pues otros miembros del consulado recurrieron a los mismos procedimientos para obtener las licencias necesarias a fin de realizar el tráfico excepcional por la mar del sur.

La participación de Francisco Ignacio de Yraeta e Isidro Antonio de Icaza en el intercambio de géneros asiáticos y europeos por cacao y plata se apoyó en las redes de negocios que habían establecido para la contratación del grano ecuatoriano, en los rendimientos que este les había generado y en las relaciones clientelares que tenían con ciertos funcionarios y oficiales reales. Las mallas de negocios que tejieron los mercaderes consulares, basadas en lazos familiares y de paisanaje, generaban una enorme confianza, la cual era absolutamente necesaria por la magnitud de las transacciones que realizaban, 
la necesidad de recurrir al crédito, la lentitud con que circulaba la información y la dificultad de las comunicaciones.

El caso Yraeta-Icaza muestra la gran relevancia que tenían las relaciones establecidas por alianzas familiares y reforzadas con enlaces conyugales. Dado que entre los vizcaínos las estrategias matrimoniales garantizaban la conservación del patrimonio y la posición social, Yraeta entregó a Icaza a su primogénita en matrimonio, lo que acrecentó la confianza mutua y reforzó sus redes de negocios. El origen común de los almaceneros favoreció el desarrollo de una relación interpersonal alimentada por una identidad cultural que valoraba la dedicación al trabajo, la lealtad y la hidalguía. Una vez que los hermanos Icaza se enriquecieron, tramitaron el testimonio de hidalguía, lo que evidencia tanto sus valores estamentales, como su interés en participar en los gobiernos municipales de la ciudad de México y el puerto de Guayaquil.

Otro de los valores centrales de la cultura vizcaína era la solidaridad entre la parentela. La integración de Icaza a su nueva familia le permitió disponer de los elevados capitales pertenecientes a la abuela de su esposa en condiciones muy favorables. Al igual que otros mercaderes del Consulado de México, Yraeta e Icaza consolidaron sus empresas con el apoyo de la familia extensa. Los tratantes procedentes de La Rioja avecin-

190 dados en ambos virreinatos también tuvieron una presencia importante en las mallas relacionales que tendieron ambos mercaderes, lo que amplió las transacciones que realizaban y la disponibilidad de fondos crediticios. Los mercaderes establecidos en Hispanoamérica se esforzaban por perpetuar los vínculos con el linaje original y los paisanos, prácticas que permitieron garantizar la unificación del imperio. 


\section{Reconocimiento}

Agradezco a Elienahí Nieves Pimentel el apoyo que me brindó en la paleografía de gran parte de los documentos que sustentan esta investigación.

Recibido: 09 de junio de 2017

Aprobado: 15 de abril de 2018

Siglas de las fuentes de archivo

AGN Archivo General de la Nación

AHH Archivo Histórico de Hacienda

AHNCM Archivo Histórico de Notarías de la ciudad de México

$\mathrm{CV} \quad$ Correspondencia de virreyes

IC Industria y Comercio

IV Indiferente virreinal

RC Reales cédulas

\section{Bibliografía}

Aguilar Gil, R.

(1999) Domingo Ramírez de Arellano: comerciante, naviero y hacendado, En C. A. Mazzeo de Vivó (Coord.), Los comerciantes limeños a fines del siglo XVIII. Capacidady cohesión de una elite 1750-1825 (pp. 175-187). Lima: Pontificia Universidad Católica del Perú. 
Arcila Farías, E.

Comercio entre México y Venezuela en los siglos XVI y XVII. México: Instituto Mexicano de Comercio Exterior.

Bonialian, $\mathrm{M}$.

(2012)

El pacifico hispanoamericano. Politica y comercio asiático en el Imperio Español, 1680-1784. México: El Colegio de México.

Borchart de Moreno, Christiana Renate

Los mercaderes y el capitalismo en México (17591778), México, Fondo de Cultura Económica.

Campillo y Cossío, J.

(1992) Nuevo sistema de gobierno económico para la América. México: Universidad Nacional Autónoma de México.

Contreras Carranza, C.

(1987) El sector exportador de una economía colonial. La costa del Ecuador entre 1760 y 1820 (Tesis para optar de grado de maestría en Ciencias Sociales). Facultad Latinoamericana de Ciencias Sociales, Programa Internacional de Maestría en Historia Andina, Lima.

Contreras Carranza, C.

(1994) Guayaquil y su región en el primer boom cacaotero (1750-1820). En J. Maiguashca (Ed.), Historia y región en el Ecuador 1830-1930 (pp. 189-250). Quito: FLACSO, Corporación Editora Nacional.

Espinoza de los Monteros, A. L.

(2008) El comercio inter-colonial. La compañía de Isidro Antonio de Icaza y Caparroso, un ejemplo del éxito empresarial novohispano, fines del siglo XVIII y principios del siglo XIX (Tesis para optar el grado de licenciatura). Universidad Nacional Autónoma de México, Facultad de Estudios Superiores Acatlán, México. 
Estrada Ycaza, J.

(1973) El puerto de Guayaquil, 2 crónica portuaria. Guayaquil, Publicaciones del Archivo Histórico de Guayas.

Flores, R.

(1999) El destino manifiesto de un mercader limeño a fines del siglo XVIII: de comerciante a consignatario, la vida y negocios de don Isidro Abarca, conde de San Isidro. En C. A. Mazzeo de Vivó (Coord.), Los comerciantes limeños a fines del siglo XVIII. Capacidady cohesión de una elite 1750-1825 (pp. 89-131). Lima: Pontificia Universidad Católica del Perú.

Flores Galindo, A.

(1984) Aristocracia y plebe. Lima 1760-1830. (Estructura de clases y sociedad colonial). Lima: Mosca Azul Editores.

García Díaz, T.

(1985) La vinculación de Francisco Ignacio de Yraeta con el mercado europeo e hispanoamericano. En M. C. Torales Pacheco (Coord.), La compañia de comercio de Francisco Ignacio de Yraeta (1767-1797), cinco ensayos (pp. 203-265). México: Instituto Mexicano de Comercio Exterior.

León Borja, D. y Szászdi, A.

(1964) Comercio de cacao de Guayaquil. Revista Historia de América, Instituto Panamericano de Historia y Geografía (57-58), enero-diciembre: 1-50.

Lamikiz, J.

(2010)

"Movilidad transatlántica: navarros en el comercio directo entre España y el Perú, 1739-1796” en Rafael Torres Sánchez (comp.), Volver a la "hora navarra". La contribución navarra a la construcción de la monarquia española en el siglo XVIII, Pamplona, Ediciones Universidad de Navarra. 
Miño Grijalva, M.

(2013) El cacao Guayaquil en Nueva España, 1774-1812 (politica imperial, mercado y consumo). México: El Colegio de México.

Pinal-Icaza, S. de.

(1994) Un miembro de la Real Sociedad Bascongada de los Amigos del País, Isidro Antonio de Icaza (17451808) y la primera generación de Icazas mexicanos. Estudio de caso. En IV Seminario de la Sociedad Bascongada de los Amigos del País. "La R.S.B.A.P. y México" (t. II, pp. 871-888).

Rodríguez Campomanes, P.

(1988) Reflexiones sobre el comercio español a Indias. Madrid, Instituto de Estudios Fiscales.

Rodríguez García, V.

El fiscal de Real Hacienda en Nueva España (Don Ramón de Posada y Soto, 1781-1793). Oviedo, Secretariado de Publicaciones de la Universidad de Oviedo.

Ruiz Rivera, J.

(1976) La casa de Ustáriz, San Ginés y compañía. En La burguesía mercantil gaditana (1650-1868) (pp. 183199). Cádiz: Instituto de Estudios Gaditanos y Diputación Provincial de Cádiz.

Soler Lizarazo, L. C.

(2010) Tráfico mercantil entre Nueva España y Guayaquil (1767-1797) (Tesis doctoral). Universidad Iberoamericana, México.

Stein, S. J.

(2001) Francisco Ignacio de Yraeta y Azcarate, almacenero de la Ciudad de México, 1732-1797. Un ensayo de microhistoria. Historia Mexicana, El Colegio de México, 50 (3): 459-512. 
Torales Pacheco, M. C. (Coord.)

(1985) La compañia de comercio de Francisco Ignacio de Yraeta (1767-1797), cinco ensayos. México: Instituto Mexicano de Comercio Exterior.

Torales Pacheco, M. C.

(1985a) Vida y relaciones de Francisco Ignacio de Yraeta. En M. C. Torales Pacheco (Coord.), La compañia de comercio de Francisco Ignacio de Yraeta (1767-1797), cinco ensayos (pp. 19-110). México, Instituto Mexicano de Comercio Exterior.

Valle Pavón, G. del.

(2007) Relaciones de negocios, familiares y de paisanaje de Manuel Rodríguez de Pedroso, conde de San Bartolomé de Xala, 1720-1770. En A. Ibarra y G. del

Valle Pavón (Coords.)

Redes sociales e instituciones comerciales en el Imperio español, siglos XVII-XIX (pp. 117-139). México: UNAM, Facultad de Economía, Instituto de Investigaciones Dr. José María Luis Mora.

Valle Pavón, G. del.

(2010) Comercialización de cacao de Guayaquil por los mercaderes del Consulado de México en la segunda mitad del siglo XVIII. Mexican Studies / Estudios Mexicanos, 26 (2): 181-206.

Valle Pavón, G. del.

(2010a) Hacendados azucareros de Cuernavaca y Cuautla miembros del consulado, su papel en la política de Nueva España a fines del siglo XVIII y principios del XIX. En E. Sánchez Santiró (Coord.), De la crisis del orden colonial al liberalismo (1760-1860), Historia de Morelos (t. V, pp. 139-166). México, Congreso del Estado de Morelos, Universidad Autónoma del Estado de Morelos. 
Valle Pavón, G. del.

(2011) Cacao de Guayaquil y apertura comercial. La promoción del comercio de cacao y azúcar a través del Consulado de México. En N. Böttcher, B. Hausberger y A. Ibarra (Coords.), Redes imperiales y negocios globales en el mundo ibérico, siglos XV-XVIII: comerciantes, financieros y corporaciones / Imperial Networks and Global Business in the Iberian World, XVth to XVIIIth Centuries: Merchants, Bankers and Corporations (pp. 239-268). Berlín: Frankfurt, Madrid, México: Instituto Ibero-Americano de Berlin; Vervuert-Iberoamericana y El Colegio de México.

Valle Pavón, G. del.

(2015) Contraprestaciones por los servicios financieros del Consulado de México y sus miembros para la guerra contra Gran Bretaña, 1779-1783. Revista Complutense de Historia de América, 41: 149-171. https:// doi.org/10.5209/rev_rcha.2015.v41.49900

Villa Estebes, D.

(1999) Liderazgo y poder: la élite comercial limeña entre el comercio libre y las guerras de independencia (el caso de Antonio Elizalde). En C. A. Mazzeo de Vivó (Coord.), Los comerciantes limeños a fines del siglo XVIII. Capacidad y cohesión de una elite 1750-1825 (pp. 133-174). Lima: Pontificia Universidad Católica del Perú.

Yuste, C.

$196 \quad$ (1985)

Francisco Ignacio de Yraeta y el comercio transpacífico. En M. C. Torales Pacheco (Coord.), La compañia de comercio de Francisco Ignacio de Yraeta (1767-1797), cinco ensayos (pp. 267-300). México: Instituto Mexicano de Comercio Exterior. 